\title{
AVALIAÇÃO FUNCIONAL DE PESSOAS IDOSAS ATENDIDAS NA ATENÇÃO BÁSICA DE SAÚDE EM UM MUNICÍPIO DO EXTREMO SUL DA BAHIA
}

\author{
AUTOR: THAÍS NADER REIS \\ CO-AUTOR: LORENA CRISTINA RAMOS OLIVEIRA \\ CO-AUTOR: CALEBE SOUZA SILVA \\ CO-AUTOR: CALILA OLIVEIRA ALVES \\ CO-AUTOR/ORIENTADOR: ANA PAULA PESSOA DE OLIVEIRA
}

Resumo: Alterações decorrentes do envelhecimento humano tendem a comprometer capacidades das pessoas idosas, como a funcionalidade. O objetivo deste estudo é o de avaliar a capacidade funcional de idosos atendidos na atenção básica de saúde em um município do extremo sul da Bahia. Trata-se de um estudo transversal, de natureza quantitativa, realizado com 50 idosos em um Estratégia de Saúde da Família da zona Leste da cidade de Teixeira de Freitas no extremo sul da Bahia. Foram aplicados 3 instrumentos de coleta de dados: questionário de caracterização sóciodemográfica, de saúde e de rede de apoio; Escala de Kartz para avaliação das ABVDs e Escala de Lawton para avaliação das AIVDs. Os resultados mostram que $65 \%$ da população idosa estudada é constituída por mulheres com idade superior a 70 anos, de ensino fundamental incompleto e com diagnóstico de diabétes e hipertensão arterial. Em ambos os sexos, a tarefa de maior dependência funcional nas ABVDs, foi a de "banhar-se" $24 \%(n=12)$ seguido de maior independência em "transferir-se" 96\% ( $n=48$ ). Já nas (AIVDs), a maior dependência foi para "finanças" 78\%(n=39); seguido de uma maior independência em transferir-se e "lavar roupa" ambos, $38 \%(n=19)$. Nesta perspectiva, os profissionais de saúde da atenção primária necessitam conhecer o cotidiano da funcionalidade da população idosa, identificando as habilidades de gerenciamento de auto cuidado comprometidas para que sejam planejadas e implementadas intervenções colaborativas.

Palavras-chave: Saúde do idoso, Funcionalidade, Atenção Primária em Saúde. 